\title{
Hand's Asymmetries in Fine Motor Precision and Speed Performance in Different Age Groups
}

\author{
Liudmila Liutsko, 1,2,3, Ruben Muiños4, and Josep Maria Tous-Ral1,2 \\ ${ }^{1}$ ISAN - International Society for Applied Neuropsychology (SPAIN, Barcelona) \\ ${ }^{2}$ Univeristy of Barcelona (SPAIN, Barcelona) (previous affiliation) \\ 3ISGlobal (SPAIN, Barcelona) \\ 4UOC (SPAIN, Barcelona)
}

Corresponding Author:

Dr. Liudmila Liutsko

Liudmila.Liutsko@Isglobal.org

Received: 25 July 2018

Accepted: 9 August 2018

Published: 1 November 2018

Publishing services provided by Knowledge E

(c) Liudmila Liutsko et al. This article is distributed under the terms of the Creative commons

Attribution License, which permits unrestricted use and redistribution provided that the original author and source are credited.

Selection and Peer-review under the responsibility of the Fifth International Luria Memorial Congress Conference Committee.

\section{Abstract}

Rose (1970) showed that women had more symmetrical precision in movements in hands, whereas men performed more asymmetrically (with dominance for right hand). These findings were congruent with Ananiev's (1968) scheme differentiated for sexes, in which for men there was a need for use of additional adaptive mechanisms (asymmetry) whereas women passed with basic ones (symmetry). Our study aimed to check the hands symmetry/asymmetry and correlations in fine motor precision and speed in both sexes and how they change in different age groups. The results of our study showed that the highest asymmetry in fine motor precision was related (for both sex groups and among all movement types) to the developmental period of life (12-17 years old) followed by group age of 64-95 due to ageing processes. In our study women performed with less asymmetry between both hands for majority of observable variables compared to men in all age groups. The highest frequency of asymmetrical performance in fine motor precision for both sexes was observed in the Frontal movement type, followed by the Transversal, and least, in the Sagittal. For the speed performance, the highest frequency of asymmetrical performance was shown in the Transversal movement type.

Keywords: fine motor precision; speed; sex differences; age-depended differences; Proprioceptive diagnostics; M.K.P.

\section{Introduction}

The fomous riddle of the Sphinx: "Which creature in the morning goes on four legs, at mid-day on two, and in the evening upon three, and the more legs it has, the weaker and slowlier it be?" Oedipus solved the riddle by answering: 
"Man-who crawls on all fours as a baby, then walks on two feet as an adult, and then walks with a cane in old age."

The famous riddle of the Sphinx reflects the trend of the gross motor activity. Similarly the quadratic shape of age-depended differences also was found in fine motor precision performance $[4,5]$.

As far as lateralization is concerned, some researchers have shown decreased hand asymmetry in motor tasks with aging [8], while others have reported faster work of the right hemisphere (left hand), which did not change much with age on non-verbal and visual tasks [10]. Research using fMRI has also identified an age-related shift from automatic to more cognitively controlled movements as subjects get older [2].

Rose (1970), with use of the Miokinetical Psychodiagnosis method [7], showed that women had more symmetrical precision in movements in hands, whereas men performed more asymmetrically (with dominance for right hand). These findings were congruent with Ananiev's (1968) scheme differentiated for sexes, in which for men there was a need for use of additional adaptive mechanisms (asymmetry) whereas women passed with basic ones (symmetry).

Our study aimed to check the hands symmetry/asymmetry in fine motor precision and speed in both sexes in different age groups. Moreover, the psychological meanings of such differences is given also based on interpretations of M.K.P. [7] and Proprioceptive Diagnostics of Temperament and Character (DP-TC; [11]) methods.

\section{Methodology}

The Proprioceptive Diagnostics of Temperament and Character (DP-TC, [11]), a digitalized version of the subtests Lineograms of M.K.P. [7], was applied in 200 participants (mean age of 33 years, range: 12-95). We observed their fine motor performance and speed in three movement types (Frontal, Transversal and Sagittal) and two sensory conditions (PV- proprioceptive-visual and $\mathrm{P}$ - proprioceptive only) represented in four age groups: $12-17 ; 18-29 ; 30-64$, and 65-95. More details on the tools, instructions can be found in the published previously articles in English [11, 12].

Two types of observable variables were used in this study:

1. for precision: LL - line length; D - directional bias; F - Formal bias) [11, 12],

2. for speed: Time spent on the performance of each task. 
The study design: two hands (dominant and non-dominant) $x$ two sensory conditions (PV - proprioception with vision and $\mathrm{P}$ - proprioceptive only) $\mathrm{x}$ three movement types (Frontal, Transversal and Sagittal).

The statistical analysis was performed with use of the SPSS v.20.

All participants took part voluntarily, were informed about the aims of the research and gave their consent prior to inclusion in the study. The study was performed according to ethical committee recommendations and in accordance with the Declaration of Helsinki on human research.

\section{Results and Discussion}

The descriptive statistics is described with details in the PhD thesis work [5]. The results below show the paired correlations (Table 1 ) and $t$-differences (Table 2) between both hands performances for the observed variables in different test conditions.

\subsection{The relationship between both hand performances in men and women in different age groups}

The highest frequency of correlations in performance was observed for speed (Time spent on task performance). In men for all movement types and age subgroups $(100 \%)$; whereas in women it was the same (100\%) in Frontal and Sagittal movements; but in Transversal movement type no statistically significant correlations were performed between both hands at age 30-64 ( $P$ and PV sensory conditions) and 12-17 (only $\mathrm{P}$ condition).

As per precision biases, depending on movement type and sensory conditions in a sum per all age subgroups we have the picture quite similar for both sexes: in five cases women had fewer correlations compared to men; in four cases vice versa, and in nine cases these indicators were equal between groups of different sexes. If analyse per each age group separately, women had fewer correlations at ages 12-17 (38\%) compared to men (46\%) and 30-64 age group (46\% vs. 58\%). Whereas in the age group of 18-29 participants of both sexes performed equally (50\% vs 50\%), and at the elder group women had slightly more statistically significant correlations met in fine precision performance ( $58 \%$ vs. $54 \%$ ). 
TABLE 1: Paired correlations between both hands.

\begin{tabular}{|c|c|c|c|c|c|c|c|c|c|c|c|}
\hline \multirow[b]{2}{*}{ MT } & \multirow[b]{2}{*}{$\mathrm{TC}$} & \multirow{2}{*}{$\begin{array}{c}\text { Age } \\
\text { group } \\
\text { Bias/Sex }\end{array}$} & \multicolumn{2}{|c|}{$12-17$} & \multicolumn{2}{|c|}{$18-29$} & \multicolumn{2}{|c|}{$30-64$} & \multicolumn{2}{|c|}{$65-95$} & \multirow[t]{2}{*}{$\% \mathrm{~F} / \mathrm{M}$} \\
\hline & & & $\mathrm{F}$ & $M$ & $\mathrm{~F}$ & $M$ & $\mathrm{~F}$ & $M$ & $\mathrm{~F}$ & $M$ & \\
\hline \multirow[t]{8}{*}{ Frontal } & $\mathrm{P}$ & LL & .50 & $.56 * \star$ & $.81 * * *$ & $.74 * \star \star$ & $.89^{* \star}$ & $.63^{* * *}$ & $.89 * \star \star$ & $.87^{* \star *}$ & $75 / 100 \%$ \\
\hline & & $D$ & $.58^{*}$ & $.48^{* \star}$ & $.73^{\star \star}$ & .18 & .36 & $.47^{\star \star \star}$ & $.63^{*}$ & .01 & $75 / 50 \%$ \\
\hline & & $\mathrm{F}$ & .35 & -.07 & -.14 & $.34^{*}$ & .31 & .09 & $.62 *$ & .15 & $25 / 25 \%$ \\
\hline & & Time & $.96 * * *$ & $.90 * * *$ & $.91 * * *$ & $.96 * * *$ & $.99 * * *$ & $.99 * * *$ & $.93^{* * *}$ & $.96 * * *$ & $\begin{array}{l}100 / \\
100 \%\end{array}$ \\
\hline & PV & $\mathrm{LL}$ & .38 & .32 & .46 & .19 & $.77^{\star}$ & $.29^{\star}$ & .37 & $.68 *$ & $25 / 50 \%$ \\
\hline & & D & .14 & $.39^{*}$ & -.01 & .13 & .39 & $.26 *$ & .09 & .12 & $0 / 50 \%$ \\
\hline & & $\mathrm{F}$ & -.45 & .23 & -.14 & .00 & .16 & -.19 & -.12 & .02 & ০/०\% \\
\hline & & Time & $.97^{\star \star *}$ & $.94^{* \star *}$ & $.92 * \star *$ & $.89 * * *$ & $.99^{* *}$ & $.96 *$ & $.88 * * *$ & $.94^{* \star *}$ & $\begin{array}{l}100 / \\
100 \%\end{array}$ \\
\hline \multirow{8}{*}{$\begin{array}{l}\text { Trans- } \\
\text { versal }\end{array}$} & $P$ & $\mathrm{LL}$ & .08 & $.55^{* *}$ & $.68 * *$ & $.45^{\star \star *}$ & $.90 * *$ & $\cdot 51^{* * *}$ & $.66 * *$ & $.78 * *$ & $75 / 100 \%$ \\
\hline & & D & .03 & -.03 & -.42 & .13 & $-.77^{*}$ & .00 & -.04 & $.60 *$ & $25 / 25 \%$ \\
\hline & & $\mathrm{F}$ & .17 & $.48 * *$ & .34 & $.29 *$ & .32 & .04 & $.67^{\star \star}$ & .16 & $25 / 50 \%$ \\
\hline & & Time & .35 & $.89 * * *$ & $.93^{* * *}$ & $.88 * * *$ & .68 & $.90 *$ & $.89 * * *$ & $.64^{* *}$ & $50 / 100 \%$ \\
\hline & PV & $\mathrm{LL}$ & -.09 & .33 & $.67^{\star *}$ & $.49 * * *$ & $.96 * * *$ & $.28 *$ & .08 & .24 & $50 / 50 \%$ \\
\hline & & $D$ & -.06 & .18 & .33 & .15 & .66 & -.20 & .11 & -.20 & ০/0\% \\
\hline & & $\mathrm{F}$ & -.12 & .15 & -.28 & .28 & .15 & .04 & $.73^{\star \star}$ & .36 & $25 / 0 \%$ \\
\hline & & Time & $.92 * \star *$ & $.88 * \star \star$ & $.88 * * *$ & $.81 * * \star$ & .58 & $.84^{\star \star}$ & $.90 * * *$ & $.82 * \star$ & $75 / 100 \%$ \\
\hline \multirow[t]{8}{*}{ Sagittal } & $P$ & $\mathrm{LL}$ & .46 & -.03 & $.80 * * *$ & $.62 * * *$ & $.94^{* \star *}$ & $.57^{\star \star *}$ & $.78 * * *$ & $.88 * * *$ & $75 / 75 \%$ \\
\hline & & $D$ & $.58^{*}$ & .22 & $.64^{*}$ & .26 & .21 & .19 & $.65^{*}$ & $.84^{* * *}$ & $75 / 25 \%$ \\
\hline & & $\mathrm{F}$ & -.47 & .04 & .02 & -.20 & -.22 & .21 & .37 & -.45 & ০/०\% \\
\hline & & Time & $.98 * * *$ & $.95^{* * *}$ & $.93^{* * *}$ & $.47^{\star \star}$ & $.93^{* * *}$ & $.96 *$ & $.95^{* * *}$ & $.80 * *$ & $\begin{array}{l}100 / \\
100 \%\end{array}$ \\
\hline & PV & $\mathrm{LL}$ & $.69^{*}$ & .24 & .13 & .02 & $.73^{*}$ & $.28 *$ & .00 & $.61^{*}$ & $50 / 50 \%$ \\
\hline & & $D$ & -.02 & -.02 & .37 & -.28 & -.24 & .25 & -.01 & .29 & o/0\% \\
\hline & & $\mathrm{F}$ & $.73^{\star *}$ & .04 & -.13 & .16 & .11 & .08 & -.51 & .39 & $25 / 0 \%$ \\
\hline & & Time & $.95^{\star \star *}$ & $.96 * * *$ & $.92 * \star *$ & $.90 * * *$ & $.93^{* \star *}$ & $.97 *$ & $.95^{* * *}$ & $.77^{\star \star}$ & $\begin{array}{l}100 / \\
100 \%\end{array}$ \\
\hline \multicolumn{3}{|c|}{$\begin{array}{l}\% \text { of significant cases } \\
\text { of total }\end{array}$} & $38 \%$ & $46 \%$ & $50 \%$ & $50 \%$ & $46 \%$ & $58 \%$ & $58 \%$ & $54 \%$ & \\
\hline
\end{tabular}

Legend: Test sensory conditions: PV - proprioceptive-visual; $\mathrm{P}$ - proprioceptive only; in bold are significant correlations ((significance level: $\left.{ }^{\star} p<.05,{ }^{\star}{ }^{\star} p<.01,{ }^{\star}{ }^{*} p<.001\right)$.

\subsection{The asymmetry in fine motor performance in men and women in different age groups}

As per results represented in Table 2, the highest percentage of asymmetrical performance (as per quantity of statistically significant differences observed) in fine motor precision and speed, the most non-harmonised age is $12-17$ for both sexes. The age 
TABLE 2: Paired differences between both hands.

\begin{tabular}{|c|c|c|c|c|c|c|c|c|c|c|c|}
\hline \multirow[b]{2}{*}{ MT } & \multirow[b]{2}{*}{ TC } & \multirow{2}{*}{$\begin{array}{c}\text { Age } \\
\text { group } \\
\text { Bias/Sex }\end{array}$} & \multicolumn{2}{|c|}{$12-17$} & \multicolumn{2}{|c|}{$18-29$} & \multicolumn{2}{|c|}{$30-64$} & \multicolumn{2}{|c|}{$65-95$} & \multirow[t]{2}{*}{$\% \mathrm{~F} / \mathrm{M}$} \\
\hline & & & $F$ & $M$ & $F$ & $M$ & $F$ & $M$ & $F$ & $M$ & \\
\hline \multirow[t]{8}{*}{ Frontal } & \multirow[t]{4}{*}{$P$} & $\mathrm{LL}$ & -0.45 & -0.20 & 0.59 & 1.04 & 0.08 & 0.08 & -0.53 & 0.83 & o/0\% \\
\hline & & D & 0.04 & $2.48^{*}$ & 0.30 & $3.08 *$ & 1.84 & $4.60 * * *$ & 1.81 & 1.06 & o/75/\% \\
\hline & & $F$ & -0.67 & -0.98 & -0.46 & 0.14 & 1.28 & -2.21 & -1.75 & 0.42 & ०/०\% \\
\hline & & Time & $-2.29^{*}$ & -1.21 & 0.78 & 0.44 & 2.35 & $-2.01 *$ & -1.14 & -1.69 & $25 / 25 \%$ \\
\hline & \multirow[t]{4}{*}{ PV } & LL & $2.37^{*}$ & 1.70 & 1.08 & $3.44^{* * *}$ & 1.80 & -2.48 * & 0.36 & 3.22 ** & $25 / 75 \%$ \\
\hline & & D & -0.64 & -0.16 & -0.89 & $-2.61^{\star}$ & -0.95 & 1.70 & 0.05 & -0.50 & $0 / 25 \%$ \\
\hline & & $\mathrm{F}$ & -0.25 & $2.47^{*}$ & -1.10 & 1.43 & -1.60 & -0.78 & 1.88 & 1.54 & $0 / 25 \%$ \\
\hline & & Time & -.60 & 1.28 & .078 & 0.19 & 1.76 & 1.61 & -1.32 & $-2.41^{*}$ & $0 / 25 \%$ \\
\hline \multirow{8}{*}{$\begin{array}{l}\text { Trans- } \\
\text { versal }\end{array}$} & \multirow[t]{4}{*}{$P$} & $\mathrm{LL}$ & 1.28 & $2.46 *$ & 1.04 & 0.66 & 0.97 & -1.22 & -1.17 & 0.95 & $0 / 25 \%$ \\
\hline & & D & 1.16 & 1.23 & -1.21 & -0.31 & -0.11 & -1.50 & 2.77 * & -0.74 & $25 / 0 \%$ \\
\hline & & $\mathrm{F}$ & 0.47 & $-2.82 * *$ & 0.23 & -1.39 & -0.19 & -0.74 & -1.88 & -1.12 & $0 / 25 \%$ \\
\hline & & Time & 0.63 & -0.92 & -0.05 & 0.42 & 1.10 & $2.61 *$ & $-2.41 *$ & $-2.76 *$ & $25 / 50 \%$ \\
\hline & \multirow[t]{4}{*}{ PV } & $\mathrm{LL}$ & 1.34 & $2.71^{*}$ & 1.25 & 0.01 & -0.12 & -1.41 & 1.93 & 1.23 & $0 / 25 \%$ \\
\hline & & D & -0.46 & 0.07 & 0.00 & -1.22 & -0.59 & -1.94 & -1.11 & -0.96 & ०/०\% \\
\hline & & $\mathrm{F}$ & $-2.24^{*}$ & -1.73 & -1.21 & -1.27 & -1.22 & -1.80 & -1.50 & -0.28 & $25 / 0 \%$ \\
\hline & & Time & $3.96 * *$ & $3.90 * * *$ & $3.67^{* *}$ & $-2.73^{\star *}$ & -0.17 & 0.92 & $2.30 *$ & -2.76 * & $75 / 75 \%$ \\
\hline \multirow[t]{8}{*}{ Sagittal } & \multirow[t]{4}{*}{$P$} & LL & $2.20 *$ & -0.03 & 0.08 & 0.91 & 0.24 & 0.13 & 0.15 & -0.20 & $25 / 0 \%$ \\
\hline & & D & -0.81 & -1.44 & -0.65 & -0.19 & -0.37 & 0.88 & -0.62 & 0.96 & ০/0\% \\
\hline & & $\mathrm{F}$ & 0.92 & 0.91 & -0.43 & -1.31 & -0.62 & -0.24 & 0.41 & -0.72 & o/०\% \\
\hline & & Time & -1.51 & -0.72 & 0.15 & 063 & 0.13 & 0.03 & -1.81 & 0.02 & ०/0\% \\
\hline & \multirow[t]{4}{*}{ PV } & LL & -0.56 & 1.00 & 0.00 & -0.54 & -1.58 & 0.03 & -0.61 & -0.02 & o/०\% \\
\hline & & D & -0.91 & -1.33 & -1.27 & -0.20 & 0.68 & 0.33 & 0.54 & 0.61 & ০/०\% \\
\hline & & $\mathrm{F}$ & 0.27 & 0.91 & 0.58 & -0.45 & -1.76 & -1.70 & -0.16 & -0.88 & ०/०\% \\
\hline & & Time & -0.93 & -2.06 * & 0.02 & -0.71 & 0.21 & 0.38 & -2.00 & -0.41 & $0 / 25 \%$ \\
\hline \multicolumn{3}{|c|}{$\begin{array}{l}\% \text { of significant cases } \\
\text { of total }\end{array}$} & $21 \%$ & $29 \%$ & $4 \%$ & $17 \%$ & $0 \%$ & $13 \%$ & $13 \%$ & $17 \%$ & \\
\hline
\end{tabular}

were the asymmetry was lowest was shown 30-64. This dynamics is related to maturation processes and further decline after the middle point to aging processes [4].

In all age groups the asymmetry in women was less frequent compared to men that confirms the previous general studies that described only line length performance (LL) [9] and theoretical work in this area [1]. However, the results of this study showed for the first time the dynamics of asymmetry/symmetry in the performance per different age groups. Moreover, they are represented in three bias types (LL - line length, $D$ - directional and $F$ - formal) and speed (Time spent on task performance), three 
movement types (Frontal, Transversal and Sagittal) and two sensory conditions (PV proprioceptive with vision and $\mathrm{P}$ - proprioceptive only).

In general, our study results suggest the existing more complex relationship of correlations and symmetry/asymmetry in fine motor precision performance and speed performance in both sexes. It depends on age, movement type and sensory condition of the test.

The psychological meaning of statistically significant differences suggest of passing via more "unbalanced" or "critical" periods of human development in general. To see more specific features, as described in

\section{Conclusions}

The highest asymmetry for both sexes was observed in age group 12-17. Women have not shown any asymmetry in the middle group ages (18-29 and 30-64). As for speed performance, the highest frequency in difference (asymmetry) was found for both sexes in Transversal movement, in all ages. For fine motor precision, the asymmetrical performance between both hands was observed in the Frontal movement type, and least, in Sagittal one.

To sum up, the results of our study confirm more symmetry (less asymmetry) between both hands performance in fine motor precision tasks in women compared to and men in all four age groups. The dynamical changes show that the percentage of the asymmetry is decreasing from the younger age group (12-17 years old) to the middle one (30-64) and then increasing again in the older group (65-95) for both sex subgroups.

\section{References}

[1] Ananiev, B.G. (1968). Человек как предмет познания. [Man as an object of knowledge] Л.: Изд-во ЛГУ, 339 с. [In Russian]

[2] Heuninckx, S., Wenderoth, N., Debaere, F., Peeters, R., \& Swinnen, S. P. (2005). Neural basis of aging: the penetration of cognition into action control. Journal of Neuroscience, 25(29), 6787-6796.

[3] Liutsko, L. (2016). Sex differences in fine motor performance (proprioceptive and visual-proprioceptive sensory conditions). PAID, 101, 495-496.

[4] Liutsko, L., Muiños, R., \& Tous, J.M. (2014). Age-related differences in proprioceptive and visuo-proprioceptive function in relation to fine motor behaviour. European 
Journal of Ageing, 11(3), 221-232. doi: 10.1007/s10433-013-0304-6.

[5] Liutsko, L. (2014). Age and sex differences in proprioception (fine motor performance). Scholars' Press, ISBN-10: 3639718372; ISBN-13: 978-3639718379

[6] Liutsko, L., Tous, J.M., Veraksa, A., \& Leonov, S. (2015). Proprioceptive indicators (precision, speed and personality) of age-depended differences for traffic security. Procedia - Social and Behavioral Sciences, 187: 491-496.

[7] Mira, E. (1958). Myokinetic psychodiagnosis. (M. K. P.) New York: Logos

[8] Przybyla, A., Haaland, K., Bagesteiro, L., Saiburg, R. (2011). Motor asymmetry reduction in older adults. Neuroscience Letters, 489(2): 99-104 http://dx.doi.org/ 10.1016/j.neulet.2010.11.074

[9] Rose, N.A. [Розе Н. А.] (1970). Психомоторика взрослого человека. [The adult's psychomotricity] Л., 1970. [In Russian]

[10] Stern, J., Oster P, \& Newport, K. (1980) Reaction time measures, hemispheric specialization, and age. In: Aging in the 1980 by Poon, L. (Ed.), Psychological issues, 309-326. doi: 10.1037/10050-022

[11] Tous Ral, J. M., Muiños, R., Tous O., \& Tous Rovirosa, J.M. (2012). Diagnóstico propioceptivo del temperamento y el carácter. Edicions Universitat Barcelona. [In Spanish]

[12] Tous Ral, J.M., \& Liutsko, L. (2014). Human errors: their psychophysical bases and the Proprioceptive Diagnosis of Temperament and Character (DP-TC) as a tool for measuring. Psychology in Russia: State of the art, 7(2).

[13] Tous-Ral, J.M., Muiños, R., Liutsko, L., \& Forero, C.G. (2012). Effects of sensory information, movement direction and hand use on fine motor precision. Perceptual and Motor Skills, 115(1): 261-272. doi: 10.2466/25.22.24.PMS.115.4.261-272 